\title{
No Association between Copy Number Variation of the TCRB Gene and the Risk of Autism Spectrum Disorder in the Korean Population
}

\author{
So Young Yang ${ }^{1,2}$, Seon-Hee Yim ${ }^{1}$, Hae-Jin \\ $\mathrm{Hu}^{1,2}$, Soon $\mathrm{Ae} \mathrm{Kim}^{3}$, Hee Jeong $\mathrm{YoO}^{4}$ and \\ Yeun-Jun Chung ${ }^{1,2 *}$
}

${ }^{1}$ Intergrated Research Center for Genome Polymorphism, '2Department of Microbiology, The Catholic University of Korea School of Medicine, Seoul 137-701, Korea, ${ }^{3}$ Department of Pharmacology, The Eulji University of School of Medicine, Daejeon 301-746, Korea, ${ }^{4}$ Department of Psychiatry, Seoul National University Bundang Hospital, Seongnam 463-707, Korea

\begin{abstract}
Although autism spectrum disorder (ASD) has been thought to have a substantial genetic background, major contributing genes have yet to be identified or successfully replicated. Immunological dysfunction has been suggested to be associated with ASD, and T cell-mediated immunity was considered important for the development of ASD. In this study, we analyzed 163 ASD subjects and 97 normal controls by genomic quantitative PCR to evaluate the association between the copy number variation of the $7 \mathrm{q} 34$ locus, harboring the TCRB gene, and ASDs. As a result, there was no significant difference of the frequency distribution of TCRB copy numbers between ASD cases and normal controls. $T C R B$ gene copy numbers ranged from 0 to 5 copies, and the frequency distribution of each copy number was similar between the two groups. The proportion of the individuals with $<2$ copies of TCRB was $52.8 \%$ (86/163) in ASD cases and $57.1 \%$ (52/91) in the control group $(p=0.44)$. The proportion of individuals with $>2$ copies of TCRB was $11.7 \%(19 / 163)$ in ASD cases and $12.1 \%(11 / 91)$ in the control group $(p=0.68)$. After the effects of sex were adjusted by logistic regression, ORs for individuals with $<2$ copies or $>2$ copies showed no significant difference compared with the diploid copy number as reference $(n=2)$. Although we could not see the positive association, our results will be valuable information for mining ASD-associated genes and for exploring the role of $\mathrm{T}$ cell immunity further in the patho-
\end{abstract}

${ }^{*}$ Corresponding author: E-mail yejun@catholic.ac.kr Tel +82-2-2258-7343, Fax +82-2-596-8969 Accepted 17 June 2010 genesis of ASD.

Keywords: autism, copy number variation, $\mathrm{T}$ cell receptor beta $(T C R B), 7 q 34$

\section{Introduction}

Autism spectrum disorders (ASDs) are complex neurodevelopmental disorders with the core features of impairment in social interaction and verbal communication and repetitive or stereotyped patterns in behavior. These disorders typically manifest within the first three years of life (Klauck, 2006).

The etiology of ASD is still largely unknown. Growing evidence has suggested a genetic background of ASD development. The concordance rates of ASD in monozygotic twins were reported to be significantly higher than in dizygotic twins, and the recurrence rates in siblings are approximately 10 times higher than in the normal population (Folstein and Rosen-Sheidley, 2001). Cytogenetic alterations were detected in $7.4 \%$ of ASDs (Vorstman et al., 2006), and some alterations have been suggested as causative factors of neurodevelopmental disorders (Merikangas et al., 2009). Several studies have revealed that ASDs are associated with genetic factors, such as single gene disorders and genetic polymorphisms, including single nucleotide polymorphisms (SNPs) and copy number variation (CNV), and that multiple genetic factors may work together (McCauley et al., 2005; Santangelo and Tsatsanis, 2005). Significant associations have been reported between ASDs and CNVs of various genes, such as NLGN3 (Xq13.1), NLGN4 (Xp22.23), SHANK3 (22q13.3), and NRXN1 (2p16.3) (Christian et al., 2008; Cook et al., 2008). However, most of these candidate genes have been neither successfully replicated in independent study populations nor functionally validated as susceptible genes or loci.

Maintaining neuronal cellular connectivity as well as synaptogenesis has been suggested to play a role in the pathologensis of ASD by trafficking of immune cells and mediators through astroglial and microglial cells (Gupta, 2000). T cell receptor beta affects TCR signaling and $T$ cell polarity (McKinney et al., 2010), which consequently affect neuronal activity, development, and plasticity (Syken and Shatz, 2003). Several association 
studies reported that an imbalance of the $\mathrm{CD} 4^{+}: \mathrm{CD} 8^{+}$ $\mathrm{T}$ cell ratio was found in children with ASDs (Denny et al., 1996; Sweeten et al., 2003).

Another interesting clue to connect the TCR with ASD is that the 7q34-35 region, where the $T$ cell receptor $B$ variable region $(T C R B)$ is located, was found to be rearranged in a patient with mental retardation, anxiety disorder, and autistic features (Dauwerse et al., 2010). In previous reports, the 7q31-34 (Risch et al., 1999) and 7q32.3-36.3 (Schanen, 2006) regions showed association with mental retardation and ASD phenotypic features (Dauwerse et al., 2010; Gu and Lupski, 2008). Based on these reports, it seems that TCRB may affect the susceptibility to neurodevelopmental disorders, including ASD.

In this study, we analyzed 163 ASD subjects and 97 normal controls by genomic quantitative PCR (qPCR) to evaluate the association between the $7 q 34$ locus, harboring the TCRB region, and ASDs and the potential diagnostic usefulness of TCRB in the Korean population.

\section{Methods}

\section{Study subjects}

We recruited 163 ASD children (137 boys and 26 girls) who were diagnosed with ASD from the Department of Child Psychiatry of Gyeongsang National University Hospital, Ghil Hospital and Seoul National University Hospital. Each proband with ASD was initially screened by two board-certified child psychiatrists according to DSM-IV criteria (American Psychiatric Association, 1994) and assessed using the Autism Diagnostic InterviewRevised (ADI-R) and the Korean version of the Autism Diagnostic Observation Schedule (ADOS). Probands with chromosomal abnormalities, such as fragile $X$ syndrome or other neurological or medical conditions suspected to be associated with ASDs, were not included. All parents or legal guardians of probands provided written informed consent for participation in this study. The normal control samples consisted of 97 Korean adult males who were free of any psychiatric or congenital disorders. This study was approved by the Institutional Review Boards of the participating institutions.

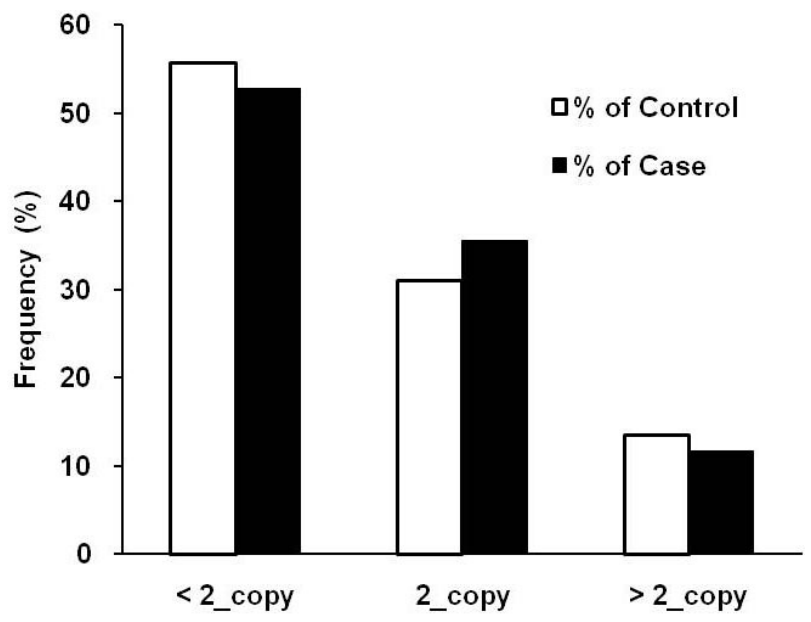

Fig. 2. Frequency distributions of TCRB gene copy numbers in ASD cases (solid bar) and normal controls (open bar).

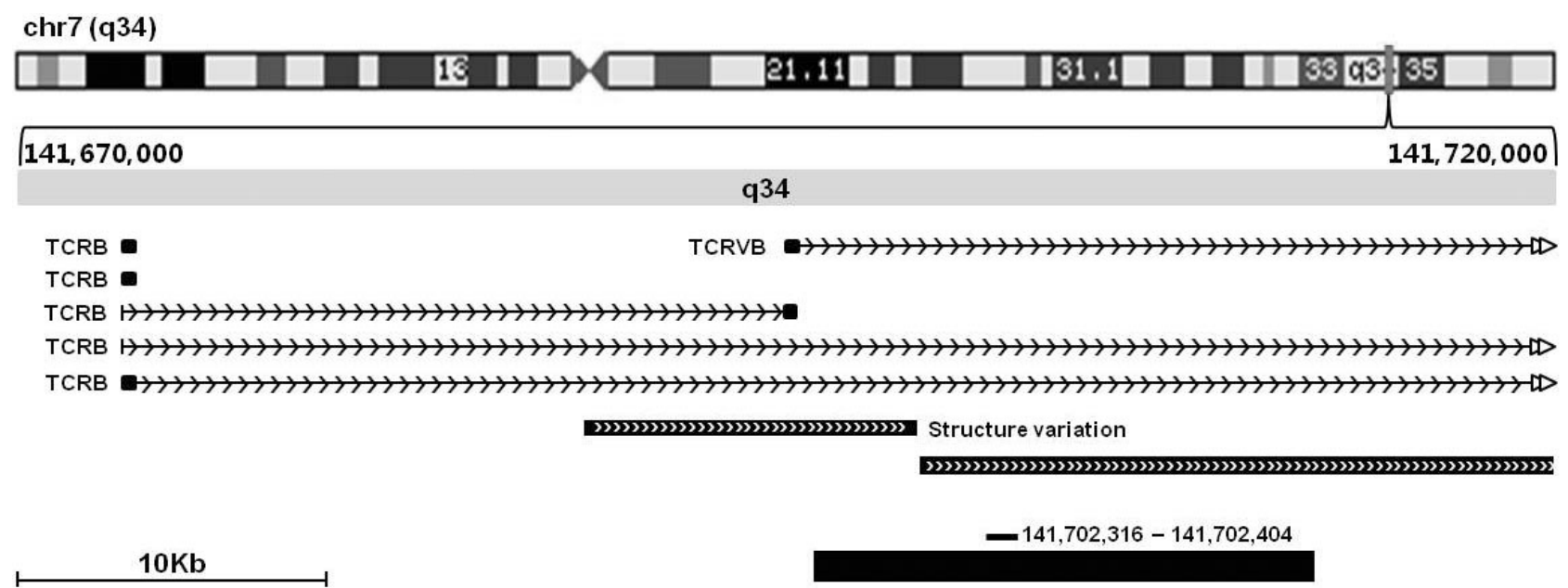

Fig. 1. Scheme of candidate region, referred by the UCSC genome browser. TCRB gene clusters stretch throughout the $7 q 34$ region. The thick solid bar ( indicates the CNV region, which was reported previously (Redon et al., 2006), and the black arrow bar $(>>>)$ indicates duplication regions as structural variations. The small narrow bar $(-)$ represents the TCBR quantitative PCR amplicon region (141,702,316-141,702,404; NCBI36). 
78 Genomics \& Informatics Vol. 8(2) 76-80, June 2010

Table 1. Frequencies and odds ratio values of TCRB copy numbers

\begin{tabular}{|c|c|c|c|c|c|c|c|}
\hline Copy & 0_copy & 1_copy & 2_copies & 3_copies & 4_copies & 5_copies & Total \\
\hline Control (\%) & $50(54.9)$ & $2(2.2)$ & $28(30.8)$ & $4(4.4)$ & $7(6.6)$ & $1(1.1)$ & $91(100)$ \\
\hline Case (\%) & $82(50.3)$ & $4(2.5)$ & $59(35.6)$ & $8(4.9)$ & $7(4.3)$ & $4(2.5)$ & $163(100)$ \\
\hline GM10851=1 copy & \multicolumn{2}{|c|}{$<2$ copies } & 2 copies & \multicolumn{3}{|c|}{$>2$ copies } & \\
\hline Control (\%) & \multicolumn{2}{|c|}{$52(57.1)$} & $28(30.8)$ & \multicolumn{3}{|c|}{$11(12.1)$} & 91 (100) \\
\hline Case (\%) & \multicolumn{2}{|c|}{$86(52.8)$} & 58 (35.6) & \multicolumn{3}{|c|}{$19(11.7)$} & $163(100)$ \\
\hline$\chi^{2}$ & \multicolumn{2}{|c|}{0.61} & & \multicolumn{3}{|c|}{0.17} & \\
\hline$p$-value & \multicolumn{2}{|c|}{0.44} & & \multicolumn{3}{|c|}{0.68} & \\
\hline Odds ratio $(95 \% \mathrm{Cl})$ & \multicolumn{2}{|c|}{$1.25(0.71 \sim 2.21)$} & 1 & \multicolumn{3}{|c|}{$0.83(0.35 \sim 2.00)$} & \\
\hline
\end{tabular}

\section{Selection of the candidate region}

To search the CNV region relevant to ASD, the Autism Chromosome Rearrangement Database (ACRD) inn the database of Genome Variants (http://projects.tcag.ca/ autism/), the autism gene database AuDB (http:// www.mindspec.org/autdb.html), and the UCSC genome browser (http://www. genome.ucsc.edu/) were used. We selected TCRB on the $7 \mathrm{q} 34$ region as the candidate region, based on an association between ASD and immunity through a literature analysis, compared it with a database of genomic variants, and chose the primer set by in silico PCR in the UCSC browser (Fig. 1). The selected region is located on the TCRB gene cluster, and it has been reported that there are many CNVs and duplication sites (Redon et al., 2006).

\section{Quantitative PCR for TCRB gene}

The primer sequences $(141,702,316-141,702,404$; NCBI build 36) of the target region are as follows: 5'-TGAGGCAGCCTGT GTGCTTTACTA-3' for forward and 5'-TAGGCTACACATGCCCTGCTACAA-3' for reverse. As a diploid internal reference gene for genomic qPCR, a gene encoding heparan sulfate, 6-O- sulfotransferase 3 (HS6ST3), was used, because neither CNV nor segmental duplication in this gene has been observed, according to the Database of Genomic Variants. The primer sequences for the internal control are as follows: 5'-CGCTACCACCACACCAAGCAG-3' for forward and 5'-CCACCTGGCTGTTGTAGTCCTC-3' for reverse. Genomic qPCR was performed using the Mx3000P qPCR system (Stratagene, La Jolla, CA). Twenty microliters of real-time qPCR mixture contained $20 \mathrm{ng}$ of genomic DNA, SYBR Premix (FINNZYMES, Finland), $1 \times$ ROX, and 10 pmol primers. Thermal cycling conditions consisted of one hot start cycle of $10 \mathrm{~min}$ at $95^{\circ} \mathrm{C}$, followed by 40 cycles of $5 \mathrm{sec}$ at $95^{\circ} \mathrm{C}, 10 \mathrm{sec}$ at $55^{\circ} \mathrm{C}$, and $20 \mathrm{sec}$ at $72^{\circ} \mathrm{C}$. After the PCR reactions, melting curve analysis was performed to confirm specific amplification. NA10851 DNA (Coriell, Camden, NJ, USA) was used as a calibrator. All GPCR experiments were performed in triplicate, and amplification efficiencies for both the target and internal reference genes were evaluated using a standard curve over serial 1:5 dilutions using MxPro Version 3.00 software. To assess efficiency of PCR amplification, the $\mathrm{Ct}$ value was determined at the cycle at which the amplicon of HS6ST3 attained the threshold of the standard curve. Relative copy number was calculated by the $\Delta \Delta \mathrm{Ct}$ method using the $\mathrm{Ct}$ values, as described elsewhere (Yim et al., 2010). The copy number

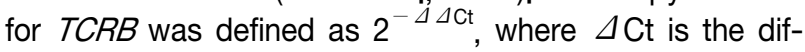
ference in threshold cycles for the sample in question, normalized against a reference gene (HS6ST3) and expressed relative to the value obtained by NA10851 DNA (individual/NA10851). We assumed the median value of the TCRB qPCR ratios in the normal control group to be diploid and adjusted all measured TCRB qPCR ratio values accordingly. Then, the adjusted ratio values were rounded off to the nearest integer.

\section{Statistical analysis}

Statistical procedures were performed using Stata software (version 10.0; Stata Corporation, College station, TX, USA). The $\chi^{2}$-test was used to test allelic differences between the case and control groups. $p<0.05$ was considered to be statistically significant.

\section{Results}

All measured copy number ratio values in TCRB and the controls were converted to integers, as described above. There was no significant difference in the frequency distribution of TCRB copy number between ASD cases and normal controls. As shown in Table 1, TCRB copy numbers ranged from 0 to 5 copies, and the frequency distribution of each copy number was similar between the two groups. The proportion of individuals with $<2$ copies of TCRB was $52.8 \%(86 / 163)$ in ASD cases and $57.1 \%(52 / 97)$ in the control group ( $p$-value= 
0.44) (Fig. 2). The proportion of individuals with $>2$ copies of TCRB was $11.7 \%$ (19/163) in ASD cases and $12.1 \%(11 / 91)$ in the control group ( $p$-value=0.68). To estimate the odds ratio (OR) of ASD, we chose the diploid copy number group as a reference point. After the effects of sex were adjusted by logistic regression, ORs for individuals with $<2$ copies or $>2$ copies showed no significant difference compared with the diploid copy number as reference $(n=2)$. Since the age variable showed a strong colinearity with the case-control status, only the effect of sex was adjusted through logistic regression. The adjusted OR was also insignificant (1.05, $95 \% \mathrm{Cl} 0.80-1.38)$.

\section{Discussion}

Immunological dysfunction has been suggested to be associated with ASD (Folstein and Rosen-Sheidley, 2001; Rutter, 2005). Especially, T cell-mediated immunity has been considered important for the development of ASD (Cohly and Panja, 2005). To maintain immune balance against numerous $\mathrm{MHC}$ molecules in the central nervous system, the rejoining of the TCR plays a role in $\mathrm{T}$ cell responses. In autistic children and their families, autoimmune disorders, such as asthma, have been reported to be more common than in the normal population (van Gent et al., 1997). Also, elevated levels of IFN- $\gamma$ in postmortem autistic patients have suggested a possible association between the pathogenesis of ASDs and impairment of $\mathrm{T}$ cell-mediated immunity (Vargas et al., 2005).

Although CNV has been suggested as a new type of genomic diversity among normal individuals, including Koreans (Freeman et al., 2006; Yim et al., 2010), it also seems to play a certain role in disease susceptibility. A number of significant CNVs on chromosome 7 and 15 have been suggested to be associated with ASD (Marshall et al., 2008). In addition, among copy number alterations, changes on chromosome 7 have been reported to be associated with various psychiatric diseases, such as ASD and mental retardation. For example, complex rearrangements on chromosome $7 q$ were identified in patients with mental retardation, anxiety disorder, and autistic features (Dauewerse et al., 2010). One of the key ASD-associated genes, named CNTNAP2, is located on 7q35 (Arking et al., 2008).

Our target locus is a variable region in TCRB. Abnormalities in TCRB have been reported to be associated with immunological defects (Currier et al., 1998; Zhao et al., 1994). Based on the previous findings described above, we hypothesized that the CNV of the TCRB gene, located on $7 \mathrm{q} 34$, may be associated with ASDs. We explored this possibility by genomic qPCR, targeting the TCRB gene, but we did not find any evidence of association.

There are several limitations of this study. First, we examined one locus to quantify the DNA copy number dosage of $T C R B$ (7q34). To represent the copy number status of this gene more reliably, several more qPCR probes must be examined in the same study subjects. Second, the study size was not large enough to make a definite conclusion.

In conclusion, there was no significant difference in $T C R B$ gene copy number between ASDs and normal individuals. An additional SNP analysis might be useful and add some more information. Although we could not see a positive association, our results will be valuable information for mining ASD-associated genes and for exploring the role of $\mathrm{T}$ cell immunity further in the pathogenesis of ASD.

\section{Acknowledgments}

This study was supported by a grant from the Korea Health 21 R\&D Project, Ministry of Health and Welfare, Republic of Korea (A040002).

\section{References}

Arking, D.E., Cutler, D.J., Brune, C.W., Teslovich, T.M., West, K., Ikeda, M., Rea, A., Guy, M., Lin, S., Cook, E.H., and Chakravarti, A. (2008). A common genetic variant in the neurexin superfamily member CNTNAP2 increases familial risk of autism. Am. J. Hum. Genet. 82, 160-164.

Bailey, A., Le Couteur, A., Gottesman, I., Bolton, P., Simonoff, E., Yuzda, E., and Rutter, M. (1995). Autism as a strongly genetic disorder: evidence from a British twin study. Psychol. Med. 25, 63-77.

Boulanger, L.M., Huh, G.S., and Shatz, C.J. (2001). Neuronal plasticity and cellular immunity: shared molecular mechanisms. Curr. Opin. Neurobiol, 11, 568-578.

Christian, S.L., Brune, C.W., Sudi, J., Kumar, R.A., Liu, S., Karamohamed, S., Badner, J.A., Matsui, S., Conroy, J., McQuaid, D., Gergel, J., Hatchwellm, E., Gilliam, T.C., Gershon, E.S., Nowak, N.J., Dobyns, W.B., and Cook, E.H. Jr. (2008). Novel submicroscopic chromosomal abnormalities detected in autism spectrum disorder. Biol. Psychiatry 63, 1111-1117.

Cohly, H.H., and Panja, A. (2005). Immunological findings in autism. Int. Rev. Neurobiol. 71, 317-341.

Cook, E.H. Jr., and Scherer, S.W. (2008). Copy-number variations associated with neuropsychiatric conditions. Nature 455, 919-923.

Currier, J.R., Deulofeut, H., Barron, K.S., Kehn, P.J., and Robinson, M.A. (1996). Mitogens, superantigens, and nominal antigens elicit distinctive patterns of TCRB CDR3 diversity. Hum. Immunol. 48, 39-51. 
Dauwerse, J.G., Ruivenkamp, C.A., Hansson, K., Marijnissen, G.M., Peters, D.J., Breuning, M.H., and HilhorstHofstee, Y. (2010). A complex chromosome $7 q$ rearrangement identified in a patient with mental retardation, anxiety disorder, and autistic features. $A m$. J. Med. Genet. A 152A, 427-433.

Denney, D.R., Frei, B.W., and Gaffney, G.R. (1996). Lymphocyte subsets and interleukin-2 receptors in autistic children. J. Autism. Dev. Disord. 26, 87-97.

Folstein, S.E., and Rosen-Sheidley, B. (2001). Genetics of autism: complex aetiology for a heterogeneous disorder. Nat. Rev. Genet. 2, 943-955.

Freeman, J.L., Perry, G.H., Feuk, L., Redon, R., McCarroll, S.A., Altshuler, D.M., Aburatani, $H_{.}$, Jones, K.W., Tyler-Smith, C., Hurles, M.E., Carter, N.P., Scherer, S.W., and Lee, C. (2006). Copy number variation: new insights in genome diversity. Genome Res. 16, 949-961.

Gu, W., and Lupski, J.R. (2008). CNV and nervous system diseases--what's new? Cytogenet. Genome Res. 123, 54-64.

Gupta, S. (2000). Immunological treatments for autism. J. Autism Dev. Disord. 30, 475-479.

Klauck, S.M. (2006). Genetics of autism spectrum disorder. Eur. J. Hum. Genet. 14, 714-720.

Marshall, C.R., Noor, A., Vincent, J.B., Lionel, A.C., Feuk, L., Skaug, J., Shago, M., Moessner, R., Pinto, D., Ren, Y., Thiruvahindrapduram, B., Fiebig, A., Schreiber, S., Friedman, J., Ketelaars, C.E., Vos, Y.J., Ficicioglu, C., Kirkpatrick, S., Nicolson, R., Sloman, L., Summers, A., Gibbons, C.A., Teebi, A., Chitayat, D., Weksberg, R., Thompson, A., Vardy, C., Crosbie, V., Luscombe, S., Baatjes, R., Zwaigenbaum, L., Roberts, W., Fernandez, B., Szatmari, P., and Scherer, S.W. (2008). Structural variation of chromosomes in autism spectrum disorder. $\mathrm{Am}$. J. Hum. Genet. 82, 477-488.

McCauley, J.L., Li, C., Jiang, L., Olson, L.M., Crockett, G., Gainer, K., Folstein, S.E., Haines, J.L., and Sutcliffe, J.S. (2005). Genome-wide and Ordered-Subset linkage analyses provide support for autism loci on $17 q$ and $19 p$ with evidence of phenotypic and interlocus genetic correlates. BMC Med. Genet. 6, 1.

Merikangas, A.K., Corvin, A.P., and Gallagher, L. (2009). Copy-number variants in neurodevelopmental disorders: promises and challenges. Trends Genet. 25, 536-544.

Redon, R., Ishikawa, S., Fitch, K.R., Feuk, L., Perry, G.H., Andrews, T.D., Fiegler, $H_{\text {., }}$ Shapero, M.H., Carson, A.R., Chen, W., Cho, E.K., Dallaire, S., Freeman, J.L., González, J.R., Gratacòs, M., Huang, J., Kalaitzopoulos, D., Komura, D., MacDonald, J.R., Marshall, C.R., Mei, R., Montgomery, L., Nishimura, K., Okamura, K., Shen, F., Somerville, M.J., Tchinda, J., Valsesia, A., Woodwark, C., Yang, F., Zhang, J., Zerjal, T., Zhang, J., Armengol, L.,
Conrad, D.F., Estivill, X., Tyler-Smith, C., Carter, N.P., Aburatani, H., Lee, C., Jones, K.W., Scherer S,W., and Hurles, M.E. (2006). Global variation in copy number in the human genome. Nature 444, 444-454.

Risch, N., Spiker, D., Lotspeich, L., Nouri, N., Hinds, D., Hallmayer, J., Kalaydjieva, L., McCague, P., Dimiceli, S., Pitts, T., Nguyen, L., Yang, J., Harper, C., Thorpe, D., Vermeer. S., Young, H., Hebert. J., Lin, A., Ferguson, J., Chiotti, C., Wiese-Slater, S., Rogers,T., Salmon, B., Nicholas, P., Petersen, P.B., Pingree, C., McMahon, W., Wong, D.L., Cavalli-Sforza, L.L., Kraemer, H.C., and Myers, R.M. (1999). A genomic screen of autism: evidence for a multilocus etiology. Am. J. Hum. Genet. 65, 493-507.

Rutter, M. (2005). Autism research: lessons from the past and prospects for the future. J. Autism Dev. Disord. 35, 241-257.

Santangelo, S.L., and Tsatsanis, K. (2005). What is known about autism: genes, brain, and behavior. $A m$. J. Pharmacogenomics 5, 71-92.

Schanen, N.C. (2006). Epigenetics of autism spectrum disorders. Hum. Mol. Genet. 15, 138-150.

Sweeten, T.L., Bowyer, S.L., Posey, D.J., Halberstadt, G.M., and McDougle, C.J. (2003). Increased prevalence of familial autoimmunity in probands with pervasive developmental disorders. Pediatrics 112, 420.

Syken, J., and Shatz, C.J. (2003). Expression of T cell receptor beta locus in central nervous system neurons. Proc. Natl. Acad. Sci. 100, 13048-13053.

Van Gent, T., Heijnen, C.J., and Treffers, P.D. (1997). Autism and the immune system. J. Child. Psychol Psychiatry 38, 337-349.

Vargas, D.L., Nascimbene, C., Krishnan, C., Zimmerman, A.W., and Pardo, C.A. (2005). Neuroglial activation and neuroinflammation in the brain of patients with autism. Ann. Neurol. 57, 67-81.

Vorstman, J.A., Staal, W.G., van Daalen, E., van Engeland, H., Hochstenbach, P.F., and Franke, L. (2006). Identification of novel autism candidate regions through analysis of reported cytogenetic abnormalities associated with autism. Mol. Psychiatry 11, 18-28.

Yim, S.H., Kim, T.M., Hu, H.J., Kim, J.H., Kim, B.J., Lee, J.Y., Han, B.G., Shin, S.H., Jung, S.H., and Chung, Y.J. (2010). Copy number variations in East-Asian population and their evolutionary and functional implications. Hum. Mol. Genet. 19, 1001-1008.

Zhao, T.M., Whitaker, S.E., and Robinson, M.A. (1994). A genetically determined insertion/deletion related polymorphism in human $\mathrm{T}$ cell receptor beta chain (TCRB) includes functional variable gene segments. J. Exp. Med. $180,1405-1414$. 